\title{
MARKETING DE RELACIONAMENTO E LOGÍSTICA NO COMÉRCIO ELETRÔNICO
}

\author{
RELATIONSHIP MARKETING AND LOGISTICS IN THE E-COMMERCE
}

\section{Ernani Cesar de Freitas}

Centro Universitário Feevale - RS

\section{Cássio Weber}

Centro Universitário Feevale - RS

\section{Mauricio Barth}

Centro Universitário Feevale - RS

\section{RESUMO}

Este trabalho se propõe a investigar e analisar as práticas existentes no Marketing de Relacionamento que se vinculam à atividade logística, tanto sob o aspecto da distribuição de produtos como de informações, para uma empresa que atua no comércio eletrônico. Para tal, faz-se um estudo em uma grande empresa varejista, presente no comércio eletrônico, principalmente nas regiões sul e sudeste do Brasil. Nesse cenário se desenvolve a importância da Logística como um componente do Marketing de Relacionamento, através do estudo de caso da unidade4 de Comércio Eletrônico das Lojas Herval. Inicialmente, uma pesquisa bibliográfica aborda as principais ferramentas que podem ser utilizadas no Comércio Eletrônico. Com base em uma pesquisa descritiva, identificaram-se resultados ou benefícios que possam ser obtidos nas transações comerciais da internet, apoiadas por uma logística adequada e que visam uma melhoria da relação com o cliente desse canal eletrônico. Ao desenvolver esta pesquisa, foram descritos de forma qualitativa e quantativa os procedimentos da organização Herval. Para a coleta dos dados, realizaram-se entrevistas não-estruturadas com os principais gestores da empresa, bem como pesquisa documental em relatórios e sistemas. A partir da análise dos dados coletados, concluiu-se que a empresa Herval possui diversos mecanismos de interação e relacionamento com seu cliente, os quais precisam ser melhorados e qualificados para serem utilizados mais intensamente.

Palavras-chave: Marketing. Logística. Relacionamento. Comércio eletrônico. Vantagem competitiva.

\section{ABSTRACT}

This study aims to investigate and analyze the practices in Relationship Marketing that link to logistics activity, for both the distribution of products and information to a company that acts in commerce. To this end, it is a study in a large retail company, present in e-commerce, mainly in south and southeastern Brazil. In this scenario develops the importance of logistics as a component of Relationship Marketing, through a case study of the unit of E-Commerce Sellers Herval. Initially, a literature review addresses the key tools that can be used in Electronic Commerce. Based on a descriptive study, we identified the results or benefits that may be obtained in commercial Internet, supported by adequate logistics and would improve the relationship with the client of the electronic media. In developing this research, were described qualitatively and quantitatively the organization's procedures Herval. To collect data, there were non-structured interviews with key managers of the company, as well as documentary research reports and systems. From the analysis of data collected, it was concluded that the company Herval has several mechanisms of interaction and relationship with his client, which must be improved and qualified to be used more intensively.

Keywords: Marketing. Logistics. Relationship. E-commerce. Competitive advantage. 


\section{INTRODUÇÃO}

O marketing assume significativa importância na administração da tecnologia de informação, pois há uma expressiva preocupação em melhor atender o cliente que não interage mais só fisicamente no ponto de venda das organizações, mas, também, na sua própria casa. A empresa passa a fazer parte do ambiente cotidiano dos consumidores, entrando em suas residências e se adaptando a suas necessidades. Para tal, a logística, sendo um conjunto de processos e parte integrante das organizações, precisa ser entendida como terceiro eixo dessa engrenagem do comércio eletrônico.

Por tudo isso, a escolha do tema deu-se pela importância que o Comércio Eletrônico vem adquirindo ao longo dos últimos anos no cenário econômico nacional e internacional, e, também, pela necessidade de auxiliar a empresa foco do estudo a reconhecer práticas presentes que podem ser utilizadas mais intensamente, ou, até mesmo, novas ferramentas que não são empregadas. A escolha da empresa Madeireira Herval Ltda, detentora da marca Lojas Herval, se deve exclusivamente pela presença de uma unidade de Comércio Eletrônico, que atende aos consumidores de todo o país através do ambiente da internet. Levando em conta proximidade, acesso a informações e segmento de negócio, trata-se de uma organização referencial para servir de objeto ao estudo proposto.

A grande questão problema que permeia o comércio eletrônico e serve para o processo de análise aqui proposto é: o Marketing de Relacionamento pode ser operacionalizado através de ações vinculadas à logística, transformando o aspecto virtual em físico, dando relevância para a distribuição de produtos e informações, que resultem em mais vendas?

Portanto, este estudo objetiva investigar e analisar as práticas existentes no Marketing de Relacionamento que se vinculam à atividade logística, tanto sob o aspecto da distribuição de produtos como de informações, para uma empresa que atua no comércio eletrônico. Através de uma análise criteriosa, buscam-se identificar possíveis resultados ou benefícios que podem ser conquistados pela empresa com essas práticas.

Para alcançar o resultado a que se propõe esta pesquisa, determinam-se alguns objetivos específicos que atuam como norteadores dos assuntos questionados e que podem auxiliar a responder ao problema de pesquisa apresentado. Esses objetivos específicos são respectivamente: descrever o atual panorama do comércio eletrônico no mercado e na Herval; apresentar o conceito de Marketing de Relacionamento e suas principais ferramentas; analisar a relação do Marketing de Relacionamento com a atividade logística, quanto à distribuição de produtos e informações na Unidade de Comércio Eletrônico; descrever o atual panorama do comércio eletrônico na empresa Herval; identificar resultados alcançados na empresa Herval com o uso do Marketing de Relacionamento nas atividades da logística, quando da atuação no Comércio Eletrônico; propor ao Comércio Eletrônico da empresa Herval melhorias do uso dos conceitos de Marketing de Relacionamento nas atividades da logística.

Para atender aos objetivos específicos propostos, a pesquisa tem como base o método do estudo de caso, com abordagem qualitativa. Neste trabalho, desenvolveu-se uma análise do Comércio Eletrônico das Lojas Herval, para que fosse possível traçar um paralelo entre a prática e a teoria existente a respeito do tema proposto.

A fim de revelar essa teoria vinculada ao Comércio Eletrônico, uma pesquisa bibliográfica foi realizada com base em diversos autores que enfocam assuntos relacionados a esse mercado, bem como aos temas de Logística e Marketing de Relacionamento.

A pesquisa documental foi outra técnica utilizada durante o estudo de caso, já que o trabalho objetiva apresentar resultados do Marketing de Relacionamento na empresa. Esta pesquisa ocorreu através de acesso a relatórios da empresa que tivessem correlação com o assunto tratado neste trabalho.

Como última técnica, porém não menos importante, fez-se uso de entrevistas não-estruturadas com gestores dos principais departamentos relacionados com o Comércio Eletrônico, para que elementos 
não vistos pela pesquisa documental pudessem servir como base de estudo.

0 trabalho apresentará, em sua fase inicial, alguns conceitos essenciais sobre Marketing de Relacionamento, Logística e Comércio Eletrônico. Após, será apresentada a metodologia utilizada no estudo, e em seguida constam os resultados e a análise. Por fim, serão apresentadas as considerações finais e as referências utilizadas na elaboração da pesquisa.

\section{MARKETING DE RELACIONAMENTO}

No estudo do Marketing de Relacionamento, procura-se identificar como, quando e por que o cliente se relaciona com a empresa. No contexto da internet, é importante que se tenha o conhecimento de ferramentas para qualificar a forma de contato da organização com o seu cliente. Busca-se aqui encontrar mecanismos que possam auxiliar o comércio eletrônico a se aproximar de seus consumidores.

O que tem se constatado na realidade, conforme trazido por Kalakota e Robinson (2002), é que atualmente os consumidores passaram a ter o comando dos mercados. É fácil para esses consumidores comparar produtos, lojas, serviços e acessar informações através de diversos mecanismos. Com este acúmulo de informações, o consumidor se torna mais experiente e, assim, mais exigente.

Grayson (2007) comenta que o consumidor é quem faz as suas regras, e se as organizações quiserem sobreviver terão que negociar com este indivíduo e se relacionar com ele. As empresas que conseguirem estabelecer relações terão maior valor que outras, mesmo que tenham mais produtos, prédios, lojas. A relação se torna um ativo indispensável, tanto quanto os funcionários.

Nesta mesma linha teórica, Morais (2009, p. 205) destaca que "o relacionamento pode determinar o valor da empresa no futuro, pois os clientes fiéis se tornam importantes ativos da empresa", ou seja, devem ser tratados como parte de seu capital.

A relação que se estabelece não será apenas um contato entre ambos, mas sim uma interação conjunta na qual será estabelecida uma troca de informações para que a venda seja concluída. 0 consumidor possui um desejo e uma necessidade descoberta ou não-descoberta a atender. Nessa relação, o principal fator a ser considerado é a possibilidade de diálogo entre consumidor e empresa. É necessário escutar o que o consumidor está dizendo às organizações.

Garry e Harwood (2009) enfatizam que as empresas estão em constante busca de clientes, porém, buscar novos clientes é sempre mais caro do que manter os existentes. Os esforços do marketing devem estar voltados a satisfazer e melhorar o desempenho dos serviços e produtos em prol dos clientes antigos que já estão satisfeitos. A prova de que um produto é bom não está na sua compra inicial, mas, sim, na sua "recompra".

Assim, "o marketing de relacionamentos implica captar e manter clientes por meio de cooperação, confiança, compromisso e compartilhamento de informações" (SHETH; ESHGHI; KRISHNAN, 2002, p. 282). Trata-se de trabalhar a manutenção dos clientes para obter dados importantes de mercado.

Las Casas e Garcia (2007) tratam da importância do relacionamento iniciar-se dentro das próprias empresas, através do entendimento dos colaboradores quanto à relevância da relação com o cliente. Ao entender o quanto esse trabalho de contato é importante, o profissional que se relaciona com o cliente terá sua autoestima melhorada e, consequentemente, vai melhorar a sua satisfação pessoal e transmitirá esse sentimento ao cliente, que também poderá ter a satisfação aumentada.

Também, nesse contexto, Giangrande et al. (1999, p. 18) relatam que "em qualquer tipo de negócio a interação com o cliente se faz via funcionário. Quem primeiro interage com cliente é o funcionário que processa os produtos ou serviços", sendo assim, a equipe interna envolvida no relacionamento com o cliente é de suma importância para o sucesso do negócio. 


\section{FIDELIZAÇÃO}

Ao entender o que contempla a fidelização, tem-se o objetivo de trazer a este trabalho uma das ferramentas utilizadas pelo marketing para manter os clientes ligados ao negócio das empresas. Sua importância está centrada no entendimento do cliente e na criação de um vínculo mais forte deste para com a organização que o atende.

O Marketing de Relacionamento focaliza o processo de fidelização dos clientes como uma possibilidade, além de gerar repetição de compra, de aumentar a credibilidade e relevância de sua empresa perante o mercado em que atua (AZEVEDO; POMERANZ, 2004). Para criar essa fidelidade, apoia-se constantemente em programas de benefícios específicos, como, por exemplo, bônus de compra cumulativos, sistemas de indicação de outros consumidores, retornos financeiros em forma de desconto, entre outros (SABATINO, 2003).

Para fidelizar, é preciso aliar dentro do Marketing de Relacionamento o atendimento personalizado, através do qual o cliente irá se sentir único através da forma como o vendedor ou equipe comercial lhe tratar, ao enfoque de tornar o cliente um parceiro de sua organização. Conforme Madruga (2006), ir além da venda propriamente dita, sendo um consultor de soluções para seu cliente e buscar através desse diferencial formar um programa efetivo de benefícios para seus clientes, pode trazer resultados financeiros que em períodos anteriores não foram conquistados.

Em uma abordagem voltada para o ambiente da internet, Karsaklian (2001) comenta que as lojas virtuais também precisam conhecer os hábitos e preferências dos clientes para poderem personalizar a sua relação para com estes. Copiando o modelo do comércio tradicional, as lojas virtuais devem estabelecer mecanismos para se relacionar com os clientes e, desta forma, iniciar o processo de fidelização, tornando a relação duradoura.

Assim sendo, Mckinley-Floyd e Shrestha (2008) destacam que a fidelização é obtida através de programas específicos que contemplem ações junto aos internautas, que inspirem a vontade de voltar a comprar no site das organizações. Cabe ressaltar que esses mesmos autores destacam a importância da facilidade de acesso e comunicação com a empresa e, também, com os processos que esta oferece, sejam eles de compra, de conteúdo de informações ou de entrega dos produtos e serviços.

\section{CRM - CUSTOMER RELATIONSHIP MANAGEMENT}

Para trabalhar com Marketing de Relacionamento, uma das ferramentas mais importantes é a informação a respeito dos clientes. Mas esta informação de nada valerá se não estiver baseada em um sistema informatizado de fácil acesso, que possa servir como princípio para a administração desse relacionamento.

Conjuntamente a isso, no estudo do relacionamento é preciso controlar as informações para que ações práticas possam ser tomadas, e essa é uma função básica da ferramenta CRM. Ela é de grande relevância para o comércio eletrônico, principalmente ao considerar a utilidade de controle das informações a respeito dos clientes, sendo necessário o seu profundo entendimento.

Ao estabelecer relações com consumidores, as empresas obtêm um fator extremamente importante: informação. Porém, gerenciar estas informações de maneira manual torna-se impraticável quando as empresas crescem e aumentam seu escopo de clientes. Para tal é necessário estabelecer padronizações e processos adequados, para que as informações provenientes das relações estabelecidas não se percam. Se isso ocorresse, certamente o relacionamento deixaria de existir, pois todos os pontos de contato com o cliente estariam prejudicados. Assim, cabe ao Marketing de Relacionamento a função de controlar e coordenar tais informações, utilizando-se do Gerenciamento de Relacionamento com Clientes (AZEVEDO; POMERANZ, 2004).

Karsaklian (2001) trata o CRM como uma qualidade que as empresas possuem de satisfazer as expectativas dos clientes em qualquer lugar a qualquer hora, sem exceções, ou seja, um sistema 
integrado entre toda a organização que tenha foco no cliente e na relação que é estabelecida com ele.

Por este motivo, Greenberg (2001) esclarece que o CRM não é tecnologia ou sistema. Trata-se de uma estratégia empresarial que define todas as atividades da organização como sendo focadas no cliente, funcionando de maneira integrada e com acessibilidade por todas as equipes da organização que possam manter contato com o cliente.

Karsaklian (2001) aborda CRM como sendo uma ferramenta que muda o pensamento da organização, estando à disposição do cliente. Portanto, não é mais o cliente que deve se enquadrar às políticas da empresa, mas sim é esta que deve estar disponível para quando o cliente desejar se relacionar. Nesse sentido, deve-se destacar que quanto maior a organização, maior também a sua complexidade. E neste momento a tecnologia torna-se imprescindível para tratar e armazenar de maneira adequada as informações dos clientes.

\section{MAIL MARKETING}

Um dos fundamentos mais importantes para o Marketing de Relacionamento é a comunicação com os clientes. Ainda mais importante na internet, esta comunicação é a responsável por atrair a atenção do cliente, assim como identificá-lo e fidelizá-lo (KARSAKLIAN, 2001).

Neste contexto, a ferramenta de e-mail marketing cumpre a função de relacionar e comunicar fatos das organizações com os seus clientes. A definição de e-mail marketing é tratada como envio de mala direta eletrônica aos clientes pertencentes à base de dados da empresa (SCHULMAN, 2009).

Em seu estudo, Morais (2009) refere o e-mail marketing como uma importante peça publicitária que atua sobre vendas, formação de marca, atualização de cadastros e relacionamentos com o cliente. Seu resultado deve estar voltado para atualizar constantemente o banco de dados e passar informações úteis aos clientes.

Conforme Limeira (2007), as principais vantagens do e-mail marketing estão centradas na rapidez, na praticidade, na possibilidade de comunicação direta e personalizada e, ainda, o baixo custo, principalmente quando comparado a outras mídias. Mas para cumprir suas funções, Limeira (2007) destaca três elementos indispensáveis para o sucesso do e-mail marketing: personalização, foco e relevância.

Azevedo e Pomeranz (2004) abordam os elementos das comunicações por e-mail marketing sob três premissas básicas: permissão, pessoalidade e relevância. As mensagens precisam ser antecipadas quanto à sua autorização de envio, pois os chamados spams quebram a possibilidade de um bom relacionamento, ou seja, é preciso que os clientes apresentem permissão para o envio a eles. Já no quesito da pessoalidade, é importante tratar os clientes de maneira customizada nas comunicações, com mensagens direcionadas e pessoais, fugindo das comunicações padrão que são enviadas para todos. Por último, Azevedo e Pomeranz (2004) tratam a relevância como o quesito que dá importância à mensagem. Para gerar atenção, é preciso que o assunto abordado seja considerado importante pelos clientes.

\section{LOGÍSTICA}

Segundo Telles e Strehlau (2006, p. 20), "a distribuição vem a ser o processo, estrutura e gestão da disponibilidade dos produtos (bens, serviços, etc) para as trocas." Assim, a distribuição pode ser classificada em duas dimensões, sendo os canais de marketing e a distribuição física.

Um completo sistema de distribuição deve ser visto de maneira ampliada do que apenas as ações que ocorrem dentro das organizações. Trata-se da formação de uma cadeia de suprimentos, que inicia na extração das matérias-primas, passa pelas organizações e relações que se estabelecem entre a origem e o processo produtivo, indo dos distribuidores e/ou vendedores até a chegada dos produtos acabados aos consumidores e seu efetivo uso, terminando apenas com o descarte destes itens. Portanto, a 
logística é algo muito mais amplo do que apenas entregar produtos (GUNDLACH et al., 2006).

Para Harrison e Hoek (2003, p. 27), a logística passa a ser então "como parte do desafio geral da cadeia de suprimentos", que é muito mais ampla. Em consonância com essa definição, Ballou (2001) enfatiza que a logística é um conjunto de atividades que serão repetidas intensamente durante todo o canal da cadeia de suprimentos por diversos agentes diferentes. Ou seja, a logística torna-se uma atividade ou função com processos diferentes para cada empresa e que depois irá compor a cadeia de suprimento.

Assim, para Harrison e Hoek (2003), a logística refere-se à gestão estratégica da compra, movimentação e armazenagem de materiais, ao controle de estoques de produtos e à coordenação do fluxo de informações relativas aos bens e serviços, em toda a organização e nos seus canais de marketing, com o objetivo de gerar lucratividade na realização dos processos de compra. Nesse sentido, Kotler e Armstrong (2003, p. 321) comentam que a logística é o processo de "levar o produto certo até o cliente certo, no lugar certo, na hora certa", envolvendo processos de marketing, administração de materiais e transporte.

\section{COMÉRCIO ELETRÔNICO}

Segundo Rao, Goldsby e Iyengar (2009), a internet passou por diversas modificações até se transformar em um canal de interação dos seres humanos através da troca de informações. "A internet é uma tecnologia aberta aos serviços de todos" (KARSAKLIAN, 2001, p. 20), o que para as empresas, representa a oportunidade de estabelecer relacionamentos com seu público-alvo.

Kotler e Armstrong (2003) definem o comércio eletrônico como sendo os processos de compra e venda realizados nos meios eletrônicos da internet. Assim, através da internet os consumidores podem identificar informações relevantes para identificar o que desejam e assim realizarem pedidos através de mecanismos de pagamento eletrônico.

Czinkota et al. (2002) afirmam que a internet é uma extensa rede capaz de facilitar as ações das organizações com a redução de custos, de estoques e a melhoria dos serviços prestados aos seus clientes. Comentam esses autores que existem diversos tipos de sites na rede, mas aqueles voltados para o conceito de comércio eletrônico serão os sites de venda, que se caracterizam por lojas virtuais, as quais possibilitam aos consumidores adquirir produtos pela internet. Mas não se trata apenas de vender.

Para Cervi et al. (2004), o comércio eletrônico compreende o uso de informações e ferramentas digitais para entender as necessidades dos clientes e, a partir deste entendimento, criar produtos e serviços personalizados através de um fornecimento no menor tempo possível. Albertin (2004) ressalta que o comércio eletrônico estabelece uma conexão direta da empresa com o cliente, sustentada pela troca de informações, podendo eliminar limites de tempo e lugar, criar uma relação de interatividade e proporcionar às organizações o desenvolvimento de inteligência empresarial para se adaptar a mudanças no comportamento do consumidor digital.

O comércio eletrônico é um ambiente de adaptação para as organizações, pois estas precisam desenvolver estratégias de interação com o cliente. Para Cervi et al. (2004), as estratégias do mercado físico e virtual precisam estar alinhadas para proporcionar diferenciação de produtos e serviços, com o intuito de criar relacionamentos com os clientes baseados em lealdade e antecipação do atendimento de suas necessidades. Harrison e Hoek (2003) tratam do alinhamento entre físico e virtual, como retrato da promessa estabelecida através dos sites e da Internet, sendo cumprido através de recursos adequados nos escritórios físicos das organizações e estratégias corretas no gerenciamento da cadeia de suprimentos e logística. 


\section{METODOLOGIA}

A metodologia é útil e necessária para descrever um modelo de aplicação para o presente trabalho, visando estabelecer o procedimento de atuação dos pesquisadores durante a prática da pesquisa.

\section{CLASSIFICAÇÃO DA PESQUISA}

Inicialmente, quanto aos objetivos utilizou-se a pesquisa descritiva como forma de apresentar o assunto abordado para solução do problema, considerando a realidade existente no ambiente onde ocorrem os fatos relevantes, através do relato destes. Coube aos pesquisadores encontrar aspectos importantes na atividade de comércio eletrônico e, posteriormente, descrevê-los, indicando como a empresa trabalha o Marketing de Relacionamento e sua relação com a Logística nas atividades da Loja Virtual.

Em relação aos procedimentos técnicos, efetuou-se uma pesquisa bibliográfica baseada na busca de conceitos estabelecidos para as áreas do Marketing de Relacionamento, da Logística e do Comércio Eletrônico. A literatura sobre o assunto serviu como base teórica para a formação das ideias e proposições do estudo, sendo que para este procedimento os pesquisadores basearam-se em informações extraídas de livros, artigos e sites.

Como outro procedimento para tratar dados específicos das atividades existentes, a pesquisa documental fez-se necessária nos três departamentos da empresa estudada, que são englobados, Marketing, Logística e Comércio Eletrônico, sendo seu conteúdo composto por relatórios provenientes do sistema de gestão da empresa Herval e de relatórios ou de pesquisas de mercado fornecidas por empresas terceiras. Assim, essa pesquisa documental apresenta tanto fontes de primeira mão, como de segunda mão.

Por fim, foram complementados os procedimentos técnicos através de um estudo de caso, que se deteve em aprofundar e detalhar o conhecimento a respeito dos temas de Marketing, de Logística e de Comércio Eletrônico utilizados na prática da empresa Herval. Assim, o estudo ficou restrito a uma empresa, para permitir novas descobertas através da observação de fatos ou fenômenos existentes que poderiam ser relacionados com o estudo teórico (PRODANOV; FREITAS, 2009).

Quanto à abordagem do problema, a pesquisa teve caráter predominantemente qualitativo, pois não se baseou apenas em números estatísticos para suas análises, mas, sim, considerou aspectos do mercado de varejo e do Marketing que podem contribuir para os resultados alcançados pela empresa. Neste ambiente, os números apenas sob a forma de resultado financeiro não traduzem todos os aspectos relevantes para o sucesso ou insucesso das práticas de Marketing adotadas pela empresa Herval que se pretende analisar com o estudo de caso. Ainda quanto à abordagem, foi necessário considerar os aspectos quantitativos. Em menor escala, mas necessários para a conclusão do trabalho, especialmente no que tange à suposição de se obter resultados financeiros ou vantagem competitiva para a empresa, a pesquisa teve que absorver em sua abordagem um caráter quantitativo.

\section{TÉCNICAS DE COLETA DE DADOS}

Segundo atestam Cervo e Bervian (1996, p. 135), "há diversas formas de coleta de dados, todas com as suas vantagens e desvantagens", tendo o pesquisador que estabelecer quais serão as técnicas mais adequadas ao seu ambiente de exploração. Portanto, neste trabalho foram previstos o uso de entrevistas e pesquisa documental, conforme segue.

A entrevista foi uma das técnicas utilizadas para a coleta de dados, sendo necessária a pesquisa junto a diversas pessoas que fazem parte da gestão da organização, relacionadas com a atividade do Comércio Eletrônico. Conforme aborda Rudio (1985), a entrevista serve para se obter respostas às indagações referentes ao assunto pretendido, sendo estas feitas pessoalmente, de forma oral ao indivíduo que está relacionado com a área de pesquisa. 
Quanto ao seu tipo, a entrevista utilizada foi não-estruturada, com perguntas abertas que possibilitaram ao entrevistador buscar mais informações do que as inicialmente previstas. Conforme Prodanov e Freitas (2009, p. 118), nesse modelo de entrevista "não existe rigidez de roteiro", sendo possível ampliar as perguntas elaboradas a fim de encontrar melhores respostas às 12 questões aplicadas.

Assim, foram realizadas cinco (5) entrevistas com os seguintes indivíduos da empresa Herval: Coordenador do Departamento de Marketing, Coordenador do Departamento de Logística, Direção e Supervisão Geral da unidade Comércio Eletrônico, Coordenador do Departamento de Tecnologia da Informação, e Gestor de Compras de produtos de Informática, todos por se tratarem de profissionais extremamente ligados às atividades de Marketing, de Logística e de Comércio Eletrônico. Essas entrevistas com os cinco indivíduos foram realizadas no período de 08 a 28 de setembro de 2009.

A amostra selecionada foi determinada a partir de indivíduos que tivessem uma efetiva relação com o tema central da pesquisa na empresa Herval. Essa amostra caracterizou-se de modo nãoprobabilístico, pois foi importante optar pela relevância das pessoas e seus cargos na empresa Herval. Dessa forma, obteve-se a amostra presente de cinco entrevistados que possuem cargos relacionados ao tema.

Por fim, cabe destacar a coleta de dados através de documentos existentes, através dos quais se buscou comprovar a realidade para tratar do assunto com mais profundidade e correlação prática, visto que as atividades focadas na observação precisavam de um embasamento real proveniente de estatísticas e números apresentados pela empresa. Ao se realizar o estudo de caso, foi necessário pesquisar fontes secundárias provenientes de relatórios elaborados pela empresa, que contemplassem as atividades de comércio eletrônico, de marketing e de logística. Todos estes aspectos da coleta de dados na pesquisa documental se basearam em abordagens quantitativas, através de números, estatísticas, projeções e relatórios.

\section{ANÁLISE E INTERPRETAÇÃO DOS DADOS}

Parte fundamental a que se propõe esta pesquisa, a análise e interpretação dos dados contribuiu para a efetiva conclusão sobre as informações coletadas. Constituiu-se como a etapa na qual as informações foram avaliadas sob algum aspecto para contribuírem com o alcance dos objetivos propostos inicialmente, e para o confronto com o problema estabelecido neste estudo. Essa análise teve como fundamental aspecto a abordagem qualitativa, já citada anteriormente, pois não somente os números de resultados conquistados com as ações de marketing foram relevantes, mas também as práticas adotadas e as ferramentas que são empregadas na empresa Herval.

Ainda na questão de análise dos dados, houve a necessidade de utilizar vínculos de abordagem quantitativa para apresentar os números e gráficos de resultado a que este trabalho se propõe. Não há como trazer os resultados sem tratá-los como dados adequados para as conclusões que puderam ser obtidas.

Já a interpretação se fez fundamental no aspecto qualitativo da abordagem, pois somente através desta é que se teve a possibilidade de expressar um significado para as informações apresentadas. Interpretar os dados é a etapa de, assim que finda a análise, entender aspectos maiores e incorporá-los às ideias formadas em pensamento. Conforme Lakatos e Marconi (1999), deve-se ir além do pensamento convencional obtido na análise dos números. É preciso encontrar fatores que tenham contribuído com os resultados da pesquisa, vinculando-os a outros conhecimentos e indo além dos números para se obter informações provenientes das práticas estabelecidas nas empresas.

A fim de se encontrar respostas para o problema levantado, na próxima seção será realizada a análise dos dados coletados conforme antes descritos. 


\section{RESULTADOS E ANÁLISE}

Ao estudar o mercado de comércio eletrônico é preciso basear qualquer pesquisa em uma realidade existente. Dessa forma, critério base para um adequado processo de análise é identificar no conjunto de lojas varejistas uma empresa que tenha alguma operação de vendas pela internet. Sendo assim, busca-se, nesta seção, analisar uma rede de lojas que atue no comércio eletrônico, através de um estudo de caso aprofundado de sua operação, para que uma análise de resultados possa ser confrontada com o referencial teórico dos temas referenciais deste trabalho.

\section{UNIDADE DO ESTUDO DE CASO}

A Madeireira Herval Ltda é um grupo de empresas situado na cidade de Dois Irmãos, Rio Grande do Sul. Está dividida em Indústria (com sete unidades de negócios: móveis, colchões de espumas, colchões de molas, solados para calçados, espumas de poliuretano, espumas de látex, dublagens a fogo e cola), Comércio (com uma rede de 65 lojas no estado do Rio Grande do Sul e Santa Catarina) e Serviços (administradora de consórcios, seguros e financeira).

Atualmente, o Grupo Herval possui aproximadamente 4.000 funcionários, atua em todo o mercado nacional, tanto com sua rede de lojas através do Comércio Eletrônico, quanto com as indústrias moveleira e química em seus respectivos produtos. Destaca-se que, na indústria moveleira, atua internacionalmente, exportando produtos para mais de 50 países.

\section{ANÁLISE DOS RESULTADOS}

Conforme depoimento do Diretor Comercial, o E-business há muito tempo deixou de ser tendência para se tornar uma necessidade na Herval. Por isso que entre as unidades do varejo é uma das que mais recebeu investimentos no ano de 2009, a fim de se preparar adequadamente para atender a uma demanda cada vez maior. Segundo o Diretor Comercial, que atua diretamente na supervisão dessa Unidade, a Loja Virtual ainda é muito incipiente, mas já supera muitas lojas pequenas da rede. Pelo fato de proporcionar bons resultados para a empresa, a Unidade merece investimentos constantes e precisa ser separada das demais lojas físicas, na forma de pensar o negócio de maneira estratégica.

Para o Coordenador de Marketing, a Unidade de E-commerce no contexto da empresa ainda precisa de uma mudança de visão para poder se destacar como atividade relevante, no que se refere a ser tratada como diferente das lojas físicas.

Ao explorar o comportamento do consumidor para o comércio eletrônico, o Coordenador de Marketing frisou que esse comportamento de compra existente na internet está intimamente relacionado com aspectos culturais da geração de consumidores, que são os aspectos ambientais de cultura, família, economia e tecnologia, referidos por Limeira (2007). O Coordenador de Marketing afirmou que o Comércio Eletrônico é um gerador potencial de inúmeras informações para a empresa, proporcionando o uso de ferramentas de marketing, vendas e relacionamento, porém, com muito mais complexidade do que no varejo tradicional.

Para resumir esta abordagem dos aspectos de comércio eletrônico presentes na empresa e de sua relevância para o posterior estudo do Marketing de Relacionamento e da logística, desenvolveu-se o Quadro 1. 
Quadro 1: Panorama do Comércio Eletrônico

\begin{tabular}{|c|c|}
\hline Objetivo & Abordagens \\
\hline $\begin{array}{l}\text { Descrever o atual panorama do } \\
\text { comércio eletrônico no mercado e } \\
\text { na Herval. }\end{array}$ & $\begin{array}{l}\text { Comércio eletrônico não é tendência, mas sim necessidade para o varejo. } \\
\text { Dentro da Herval ainda é pequeno, é visto ainda como uma loja física. É } \\
\text { uma das unidades com melhor crescimento. } \\
\text { Deve ser uma unidade separada da rede de lojas físicas. } \\
\text { Demanda investimentos constantes. } \\
\text { Proporciona ótimos resultados. } \\
\text { Está relacionado a aspectos culturais do consumidor. } \\
\text { Proporciona diversas ferramentas acessíveis para gerar relacionamento, } \\
\text { mas é mais detalhista e complexo por se relacionar com inúmeros públicos. } \\
\text { Grande interação com a logística, inclusive já recebe tratamento } \\
\text { diferenciado em todo o processo logístico. } \\
\text { Forte interação com o TI. É o que sustenta o comércio eletrônico ao lado } \\
\text { da logística e do marketing. } \\
\text { Gera demanda para compras, que proporciona os produtos dentro de } \\
\text { condições comerciais para que o comércio eletrônico possa ser ompetitivo. }\end{array}$ \\
\hline
\end{tabular}

Fonte: elaborado pelos autores

Quando questionados a respeito do uso do Marketing de Relacionamento, os gestores destacaram, com exceção do Coordenador de TI, que este não é realizado de maneira sistêmica. Madruga (2006) assevera que a prática do Marketing de Relacionamento está diretamente ligada à utilização de ferramentas de Gerenciamento de Relacionamentos com o Cliente, os conhecidos sistemas de CRM. Porém, na realidade, a essência do Marketing de Relacionamento trata de cooperação, de confiança, do compromisso e do compartilhamento de informações entre cliente e empresa (SHETH; ESHGHI; KRISHNAN, 2002). E essa relação é a essência da prática adotada pela empresa Herval, sem mecanismos sistemáticos, mas com abordagens da loja para com os clientes.

o Coordenador de Marketing destacou a ausência de programas de clientes preferenciais, mas a fidelização é identificada no Comércio Eletrônico pelos relatórios de Ranking de Clientes, onde os principais são aqueles que realmente repetem transações constantemente, sendo esta relação de preferência embasada por comunicações como o e-mail marketing e principalmente o Contact Center. Conforme mostra o Quadro 2, a empresa pode monitorar o perfil do cliente, identificando região, tipo de produtos e frequência de compras, em um rápido relatório extraído do sistema de gerenciamento do site. Isso demonstra a interatividade do cliente com o canal de compras do Comércio Eletrônico, e retrata um micromecanismo que contribui para o acompanhamento do relacionamento da Loja Virtual com o seu cliente.

Quadro 2: Perfil de Compras do Ranking de Clientes, período 2008/2009

\begin{tabular}{|c|c|c|c|c|}
\hline \multicolumn{5}{|c|}{ PERFIL DE COMPRAS - 10 maiores clientes - 2008/2009 } \\
\hline Consumidor & Linha de produtos & Pedidos & Cidade & Estado \\
\hline Cliente A & $\begin{array}{l}\text { Informática } \\
\text { Eletrônicos, } \\
\text { Eletrodomésticos }\end{array}$ & 47 & Dois Irmãos & RS \\
\hline Cliente B & $\begin{array}{l}\text { Informática, } \\
\text { Eletrônicos, } \\
\text { Utilidades, } \\
\text { Ferramentas }\end{array}$ & 71 & Dois Irmãos & RS \\
\hline Cliente C & Informática & 10 & Florianópolis & $\mathrm{SC}$ \\
\hline Cliente D & Ferramentas & 13 & Arroio dos Ratos & RS \\
\hline Cliente E & Informática & 10 & São Paulo & SP \\
\hline Cliente F & Informática & 5 & Porto Alegre & RS \\
\hline Cliente G & $\begin{array}{l}\text { Informática } \\
\text { Eletrodomésticos }\end{array}$ & 17 & Dois Irmãos & RS \\
\hline Cliente H & Informática & 5 & Porto Alegre & RS \\
\hline Cliente I & Ferramentas & 3 & Belo Horizonte & MG \\
\hline Cliente K & Ferramentas & 5 & Salvador & BA \\
\hline
\end{tabular}

Fonte: adaptado do Sistema Comercial da empresa Herval 
Segundo o que se pode observar nesse Quadro 2, os clientes que mais repetem compras são aqueles que se relacionam com a empresa pela proximidade e aspectos culturais, visto que são da cidade de Dois Irmãos, Rio Grande do Sul. Porém, cabe ressaltar, que mesmo a empresa não informando o valor financeiro das transações, existem outros clientes que estão no ranking dos 10 maiores, mas efetuam poucas compras. Mesmo assim, há repetição de compras. Com essas informações, a empresa conhece seu consumidor, qual o seu perfil de compra e pode intervir nesse relacionamento para torná-lo mais produtivo, seja através de contato telefônico, de e-mail, de correspondência ou quaisquer outros mecanismos que tenha à disposição.

Na Herval, em se tratando de E-business, outra prática de relacionamento é o e-mail marketing já comentado. Sua periodicidade de envio é semanal, havendo incremento dessa prática em campanhas de datas comemorativas, como Natal, Dia das Mães, Dia dos Pais, entre outras, podendo passar para dois ou três envios semanais. Conforme mostra o Gráfico 1, os acessos conquistados com essa ferramenta tiveram forte crescimento.

Gráfico 1: Envio de E-mail Marketing em datas comemorativas - período 2008/2009

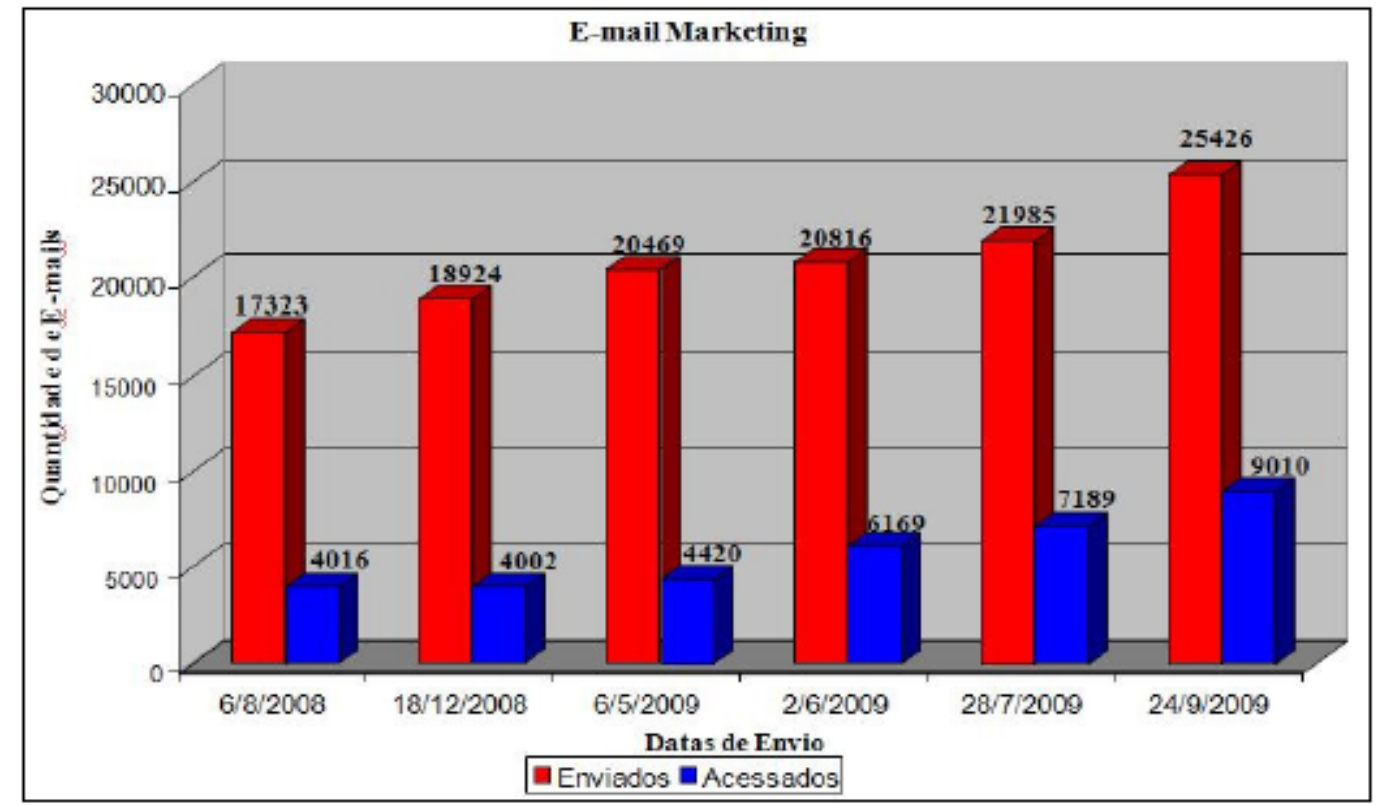

Fonte: adaptado do Sistema de E-mail Marketing da Loja Virtual Herval

No Gráfico 1, observou-se que há um crescimento do volume de envios e o número de acessos acompanha essa tendência. Mesmo não dispondo dos dados completos de envio de e-mails marketing, pois este Gráfico 1 explora apenas algumas datas e os envios são segmentados para grupos de clientes da base, fica perceptível a função de incremento em acessos através das campanhas de e-mail marketing. Para campanhas de e-mail marketing, a empresa E-bit (2009) informa que no Brasil a média é de que $2 \%$ dos acessos do comércio eletrônico se concretizam em vendas. Ao analisar os números do Comércio Eletrônico da Herval e supor esse percentual de média em compras, em setembro de 2009, com 9.010 acessos na campanha, a Empresa incrementou em 180 pedidos o seu volume normal, que perfaz um percentual de $2 \%$ do total de acessos.

Com o intuito de enfatizar os aspectos trazidos da coleta de informações, a respeito do Marketing de Relacionamento, na visão dos gestores da Herval, foram resumidos os aspectos relevantes presentes na análise através do Quadro 3 com a síntese deste tema, conforme segue. 
Quadro 3: Marketing de Relacionamento - conceitos e ferramentas

\begin{tabular}{|l|l|}
\hline \multicolumn{1}{|c|}{ Objetivo } & \multicolumn{1}{c|}{ Abordagens } \\
\hline $\begin{array}{l}\text { Apresentar o } \\
\text { conceito de } \\
\text { Marketing de } \\
\text { Relacionamento } \\
\text { e suas }\end{array}$ & $\begin{array}{l}\text { - Marketing: é estratégico, pois pensa o mercado para a realização de negócios; focado em } \\
\text { atender a necessidades do mercado; é fundamental para vendas, para trazer o cliente até o } \\
\text { principais } \\
\text { ferramentas }\end{array}$ \\
& $\begin{array}{l}\text { - Relacionamento: fundamental para serviços; atividade de pensar o cliente para o futuro, } \\
\text { como pessoa; confiança no serviço ou produto; }\end{array}$ \\
& $\begin{array}{l}\text { - Marketing de Relacionamento: forma de gerar vínculos entre cliente e empresa, fazendo } \\
\text { - Base da atividade é mesclada entre produtos e serviços. }\end{array}$ \\
& $\begin{array}{l}\text { - Vantagem competitiva: lembrança na mente do cliente; relacionamento é duradouro; quando } \\
\text { relacionamento é fidelizar o cliente; relacionamento através de ferramentas de TI; }\end{array}$ \\
& - Na Herval relacionamento existe, mas não é tratado de forma sistêmica. \\
& - Relacionamento se baseia na figura do vendedor ou atendente \\
& - Pontos de contato para relacionamento: logística, comunicação, atendimento. \\
& - Ferramentas utilizadas: $e$-mail marketing, contact center, chat online, CRM (apenas uma \\
&
\end{tabular}

Fonte: elaborado pelos autores

Quando questionados a respeito da entrega de informações, todos os entrevistados foram unânimes em afirmar que este processo é fundamental para a efetivação de negócios na internet. Segundo o Coordenador de Marketing, "ganha a venda quem entregar mais e melhores informações". Já para o Coordenador de Logística a informação assume o papel do vendedor, quando compara-se o meio eletrônico com o físico. Com a falta de informação adequada, pode-se deixar de concretizar negócios. A esse respeito, Reedy, Schullo e Zimmerman (2001) afirmam que a informação e o conteúdo são aspectos intangíveis presentes em sites que não são entregues, mas se materializam através dos produtos comercializados.

Assim, em outra questão, indagados sobre a capacidade do comércio eletrônico tangibilizar todo o seu conteúdo virtual presente na internet, a logística foi destacada como mecanismo indispensável para esse processo. Transformar uma imagem em um produto diante dos olhos do cliente, o qual ele irá tocar e usufruir, é fruto de um processo adequado de logística. O Gestor de Compras ressaltou que "o atendimento prestado, seja via e-mail, call Center, chat online ou outro meio qualquer, se for personalizado, poderá materializar para o cliente um desejo de compra". Borges (2006) identifica que a diferenciação do processo logístico, desde a venda até a entrega pode ser relevante para a experiência e avaliação da compra por parte do cliente.

Para o Coordenador de Marketing, a interação desse marketing com a logística está justamente no processo de entrega. Para esse gestor, "a simples função de manter o cliente informado de como o seu produto está sendo encaminhado, onde está e quando irá chegar, já possibilita uma interação", no sentido de atender a uma necessidade do cliente. Ou seja, deixá-lo seguro, informado e como se estivesse realmente no controle da situação, ainda mais num processo de Comércio Eletrônico no qual não há qualquer aspecto físico ao qual o cliente possa se basear até o ato da entrega em si.

Um dos aspectos importantes da logística quanto a marketing foi retratado pelo Coordenador de Logística, ao mencionar que esta pode melhorar ou piorar a imagem da empresa. Quem trata de imagem é o marketing, sendo que este precisa estar próximo da logística para que os processos estejam alinhados com o intuito de garantir uma boa imagem. Também ressalta o Gestor de Compras, que "é a logística que deve se adaptar ao cliente e não o cliente às práticas impostas pela organização". Para Harrison e Hoek (2003), a logística deve entregar o produto certo, no local certo e na hora certa, e complementam: conforme o cliente tiver determinado previamente. Para exemplificar os aspectos de interação do marketing com a logística, elaborou-se o Quadro 4 com os principais elementos apurados. 
Quadro 4: Relação Marketing de Relacionamento e Logística

\begin{tabular}{|c|c|}
\hline Objetivo & Abordagens \\
\hline $\begin{array}{l}\text { Analisar a relação do } \\
\text { Marketing de } \\
\text { Relacionamento com } \\
\text { a atividade logística, } \\
\text { quanto à distribuiçăo } \\
\text { de produtos e } \\
\text { informações na } \\
\text { Unidade de } \\
\text { Comércio Eletrônico }\end{array}$ & $\begin{array}{l}\text { - Importância da informação no comércio eletrônico: (a) informaçāo é aspecto } \\
\text { decisivo para a venda, porque năo há o papel do vendedor presencial; (b) informação } \\
\text { é fundamental pois é a base da conveniência. O acesso a ela é muito facilitado nesse } \\
\text { ambiente e por isso ela precisa estar completa; (c) a informaçăo gera visitas ao site } \\
\text { que podem ser convertidas em vendas. } \\
\text { - Característica da informaçāo: (a) deve ser completa, ágil e confiável, tanto no site } \\
\text { como via SAC ou Call Center; (b) quem proporciona mais informações no comércio } \\
\text { eletrônico tem maior volume de vendas. } \\
\text { - Aspectos virtuais tangibilizados: (a) informação; (b) logística; (c) pós-venda; (d) } \\
\text { segurança; (e) prazos de entrega; (f) qualidade do produto; (g) atendimento; (h) } \\
\text { possibilidade de personalização. } \\
\text { - Relaçăo Marketing X Logística: (a) entrega é o básico. Fazer a mais em prazo, } \\
\text { qualidade e atendimento na logística é diferencial de mercado; (b) forma de entrega } \\
\text { pode ter condições agregadas que tornam o serviço mais completo; (c) serviços } \\
\text { agregados que provêm do marketing: cordialidade dos entregadores, fornecimento de } \\
\text { informações de produtos; (d) ações logísticas impactam na imagem da empresa; (e) } \\
\text { empresa se adaptar ao cliente e năo o contrário. }\end{array}$ \\
\hline
\end{tabular}

Fonte: elaborado pelos autores

Questionado sobre os benefícios do marketing de relacionamento, o Diretor da empresa Herval disse que "o principal é o cliente voltar a fazer negócios com a organização", influenciado justamente por esse relacionamento. Ou seja, a quantidade de vezes que o cliente se relaciona com a empresa pode ser um indicador desse relacionamento estabelecido. Conforme estudado por Telles e Strehlau (2006), o comércio eletrônico alterou a forma como os clientes realizam o processo de compra. Se há repetição desse processo, o volume dessa repetição poderá, sim, indicar como está a empresa no quesito relacionamento.

Quando indagados a respeito da logística como ferramenta de relacionamento, todos os gestores colocaram de maneira enfática que um processo inadequado pode afetar toda a entrega de informação anterior, todo o bom atendimento do Contact Center e a flexibilidade ou agilidade do processo de compra pelo site. Por isso, a logística é fonte e complementação de relacionamentos com o cliente. Um relacionamento pode ser quebrado pela falha no processo, o que, segundo o Diretor da empresa, acarreta perda de confiança. Em contrapartida, o Diretor mencionou que "a boa logística contribui para o incremento da confiança do cliente na empresa, mais ainda quando se fala em comércio eletrônico". Para o setor de Marketing, o principal resultado a ser obtido pelo relacionamento do cliente para com a empresa é a compra bem sucedida. Para o Coordenador desse departamento, se o cliente consegue encontrar o que procura no site, receber o produto, no mínimo como desejado, e, se preciso for, ter um processo de pós-venda adequado, ele estará tendo uma experimentação incrementada pela essência de a empresa fazer o que ele necessitava naquele momento. Com essa experiência de compra e de relacionamento com a ferramenta que é o site e as suas estruturas de apoio, as vendas poderão ser desenvolvidas consideravelmente.

Com o intuito de sintetizar as informações obtidas durante o processo de pesquisa, foi desenvolvido o Quadro 5, com a abordagem dos resultados conquistados pelo Marketing de Relacionamento, na Herval. 
Quadro 5: Marketing de Relacionamento - Resultados

\begin{tabular}{|c|c|}
\hline Objetivo & Abordagens \\
\hline $\begin{array}{l}\text { Identificar resultados } \\
\text { alcançados com o uso do } \\
\text { Marketing de } \\
\text { Relacionamento nas } \\
\text { atividades da logística, } \\
\text { quando da atuaçăo no } \\
\text { Comércio Eletrônico }\end{array}$ & $\begin{array}{l}\text { Principal benefício do relacionamento: cliente voltar a fazer negócios com a } \\
\text { empresa; ser o primeiro a estar na lembrança do cliente; aumento de vendas e } \\
\text { lucro; melhora da imagem da empresa; cliente ver a empresa como provedora } \\
\text { da solução que ele precisa. } \\
\text { Resultado percebido: (a) clientes pedem por vendedores específicos quando do } \\
\text { atendimento para compra de produtos. Mais perceptível nas cidades do interior, } \\
\text { mas presente em toda a rede. (b) clientes adquirem produtos ou serviços por } \\
\text { indicação de outros. (c) aumento de vendas em ações específicas. } \\
\text { Resultado do Relacionamento: é afetado pela logística no processo de entrega. } \\
\text { Incremento de Vendas: pela confiança adquirida ao entregar produtos e } \\
\text { informações; pela experiência de compra bem sucedida; pelo atendimento ao } \\
\text { entregar produtos e informações; pela agilidade e flexibilidade ao } \\
\text { disponibilizar informações; pela personalização de processos. }\end{array}$ \\
\hline
\end{tabular}

Fonte: elaborado pelos autores

Observou-se, na empresa Herval, que é possível encontrar alternativas de melhoria das práticas vigentes de relacionamento, as ferramentas utilizadas podem ser melhoradas, principalmente por um apoio maior da área de Tecnologia da Informação. Conforme o Coordenador de TI afirmou, "as ferramentas de relacionamento estão presentes, mas precisam ser utilizadas com maior frequência. A empresa que fizer uso melhor do TI para elaborar ferramentas de gestão terá uma vantagem competitiva". Sendo assim, ressaltou-se a necessidade da empresa investir tempo e capital para expandir o uso de práticas como e-mail marketing, Contact Center ou outras que sejam possíveis encontrar.

Para a área da Logística, as melhorias no relacionamento podem ser feitas através de treinamentos com os responsáveis pelos momentos de contato com o cliente no processo de entrega, não só de produtos como de informações. "A gente tem muito o que fazer ainda, treinar, trabalhar a equipe, para que o atendimento na entrega seja cordial e eficiente" (COORDENADOR DE LOGÍSTICA, 2009). Para a empresa, também é fundamental o procedimento feito pelo Contact Center, como percebido pelos números de atendimento. Nesse contexto, o bom treinamento da equipe é muito importante e, hoje, a empresa não possui uma política constante de treinamentos para atender a essa demanda do Contact Center.

Terminada a análise sobre as questões que foram levantadas para este estudo, é preciso complementála com algumas discussões pertinentes que são abordadas no próximo tópico.

\section{DISCUSSÃO DA ANÁLISE}

Um ambiente dinâmico, flexível, dotado de forte capacidade de adaptabilidade e interação com o ser humano e, também, com dimensões ainda não completamente exploradas. Dessa forma deve ser compreendido o universo do comércio eletrônico, principalmente no cenário brasileiro. Um mercado em forte expansão, que marca não só uma tendência, mas sim uma necessidade de melhor uso do tempo e do espaço por parte das pessoas, que, com cada vez mais frequência, transformam-se em consumidores, os novos e-clientes ou consumidores eletrônicos, vorazes por tornar seu dia-a-dia mais produtivo, e para tal, as empresas precisam entender o porquê dos clientes buscarem as compras online. Economia de tempo? Preços e condições mais acessíveis? Processo de compra mais dinâmico ou menos burocrático? Fuga das interações pessoais no momento da compra para agilizar o processo de aquisição? Todos estes podem ser motivos impulsionadores das compras online. Mas cabe às organizações pensar como clientes e olhar para seus processos como se estivessem realizando uma compra, ou seja, se colocar no papel das pessoas que compram.

Por isso, o Comércio Eletrônico, o Marketing e a Logística sempre andarão juntos. O Marketing fornece uma promessa e a Logística a faz cumprir. Esse é o mecanismo, e as margens para falhas operacionais são muito pequenas. 0 cliente que compra através de uma loja virtual confia em uma informação 
disponibilizada através de um sistema de tecnologia.

O site da empresa tem um papel fundamental, por isso a importância da Tecnologia da Informação. Ela dá suporte para que esse contato digital aconteça. Ele é que inicia o relacionamento do cliente com a empresa. Esse relacionamento irá se estender pela entrega de informações, passar pelo contato físico na entrega e no uso do produto, e terminar em um trabalho de pós-venda realizado com o intuito de descobrir mais necessidades ocultas dos clientes.

Neste trabalho, buscou-se entender como o Marketing de Relacionamento pode influenciar ou ser influenciado pelas atividades da logística. O contato físico do cliente no comércio eletrônico ocorre apenas com a entrega efetiva da promessa de produto que lhe foi feita no site. Esse é um momento da verdade, no qual a empresa confirma para esse cliente o quão eficaz ela é no atendimento àquilo que foi solicitado.

Através do estudo de caso, foi possível identificar que esse momento de contato, tanto pelo site ou pelo sistema de informações, como pelo ato da entrega física de um produto, é muito importante para uma experiência de compra positiva na mente do cliente. Qualquer falha nesse caminho pode acarretar a quebra de uma boa imagem conquistada em momentos anteriores, ou mesmo aumentada em momentos posteriores. Apesar de a empresa Herval não possuir um controle sistêmico desse relacionamento e da interação marketing X logística, a organização tem o pleno conhecimento de que existem benefícios efetivos com um adequado funcionamento das etapas que contemplam os momentos de contato do cliente com a Empresa. E para ela isso é base essencial de um bom relacionamento.

Assim, estando concluído o processo de análise dos dados pesquisados, torna-se possível passar às considerações finais sobre este estudo.

\section{CONSIDERAÇÕES FINAIS}

Ao entender que o comércio eletrônico como atividade geradora de negócios deixou de ser uma tendência para ser uma necessidade, como canal de vendas que atende a um novo público de consumidores que já possui grande relevância, as empresas passam a estar mais presentes e próximas do mercado em que atuam. Essa presença cria um relacionamento contínuo, sendo que os clientes, através da internet, podem obter o que precisam a qualquer hora, de qualquer lugar.

Este trabalho se propôs a analisar a operação do Marketing de Relacionamento através de ações vinculadas à logística, onde aspectos virtuais do ambiente eletrônico pudessem ser transformados em aspectos físicos, seja sob a forma de produtos ou de informações entregues aos clientes. Esses aspectos físicos do relacionamento poderiam proporcionar incremento de vendas? Ao final da análise, os pesquisadores acreditam que o problema de pesquisa apresentado é relevante e pode ser esclarecido através do estudo de caso da empresa Herval no segmento de comércio eletrônico. Há possibilidade de criação de relacionamentos comerciais fortes na internet, principalmente para a atividade de lojas virtuais quando o consumidor pode perceber aspectos tangíveis em algo puramente intangível como um site. A informação obtida de maneira fácil ou o produto entregue com agilidade são aspectos levantados na análise que atendem ao problema de pesquisa, ao demonstrarem que os clientes avaliam estes aspectos quando efetuam compras no canal de comércio eletrônico.

E a empresa reconhece isso na figura de seus gestores, que estão interados da necessidade de atender a essa demanda dos clientes por informações e produtos.

Ao trazer o problema das práticas de relacionamento através da logística, o trabalho buscou comprovar que esse exercício de marketing é fundamental ao criar valor para essa atividade logística. Conseguiu-se evidenciar que mesmo não sendo uma prática padronizada, o relacionamento é considerado pela empresa como importante e pode sim gerar maior volume de vendas. Somente é preciso melhorar os seus controles e ferramentas para que possa trazer mais resultados. 
Este trabalho propunha investigar e analisar as práticas do Marketing de Relacionamento que se vinculam à atividade logística. 0 resultado apresentado na análise destacou diversas ferramentas utilizadas pela Unidade de Comércio Eletrônico da Herval, sendo que muitas delas estavam intimamente ligadas a todo o processo logístico. Essas ferramentas são de grande relevância, principalmente no aspecto de entrega de informações.

A grande contribuição deste trabalho está na esfera da construção de um conhecimento mais amplo a respeito do que um relacionamento pode acarretar aos resultados de uma empresa. Há sim incremento de vendas quando compras são repetidas e o cliente se sente parte integrante da filosofia de uma empresa. Fica o aprendizado de que se pode gerar receitas através de um atendimento qualificado e da verdadeira importância das ações planejadas, com foco em atender ao que o cliente anseia e não apenas ao objetivo exclusivo de se obter lucros com vendas em escala.

Houve, como grande limitador para a pesquisa, o fato de que os pesquisadores tiveram que buscar informações que não estavam disponíveis em relatórios totalmente prontos, mas em módulos separados que poderiam ser integrados uns aos outros pelo uso da tecnologia de sistemas. Mesmo com essa limitação, os objetivos puderam ser atendidos.

Por todo o exposto, fica, inclusive, como possibilidade para estudos futuros, a tarefa de se comparar a mesma empresa daqui a alguns anos, quanto aos mesmos assuntos, para poder traçar um comparativo entre o processo incipiente que ocorre hoje com o que poderá ser realizado com o poder de informação que existe no negócio do comércio eletrônico. Além disso, é possível ampliar horizontes, identificando como o cliente está enxergando e avaliando as ferramentas de relacionamento que são utilizadas pela empresa. Também, estudo semelhante poderá ser desenvolvido em outras empresas que atuem no comercio eletrônico.

Este trabalho também poderá contribuir como complementação de outras pesquisas nas áreas de Comércio Eletrônico e Marketing de Relacionamento, por trazer diversos conceitos e práticas desses segmentos. Outros estudos derivados também podem ser gerados como explorações nas áreas de Tecnologia de Informação ou Logística, que objetivem melhorar os resultados operacionais das empresas em função de atividades de relacionamento.

Enfim, com a pesquisa que neste trabalho se desencadeou, novas possibilidades podem ser exploradas, mas fica o sentimento de que um primeiro passo já foi dado para a construção de um conhecimento aprofundado sobre as alternativas existentes para o comércio eletrônico brasileiro.

\section{REFERÊNCIAS}

ALBERTIN, Alberto Luiz. Comércio eletrônico: modelo, aspectos e contribuições de sua aplicação. São Paulo, SP: Atlas, 2004.

AZEVEDO, Abaeté de; POMERANZ, Ricardo. Marketing de resultados. São Paulo: Makron Books, 2004.

BALLOU, Ronald H. Gerenciamento da cadeia de suprimentos: planejamento, organização e logística empresarial. 4. ed. Porto Alegre: Bookman, 2001.

BORGES, Marcelo Alexandre. Gerenciamento de cadeia logística: oportunidades de criação de valor através da logística de distribuição. Gestão e Desenvolvimento, Novo Hamburgo, RS, v. 3, n.1, p. 4956, jan. 2006.

CERVI, Osvaldo de Salles Guerra et al. Marketing operacional. São Paulo: DVS Editora, 2004.

CERVO, Amado Luiz; BERVIAN, Pedro Alcino. Metodologia Científica. 4. ed. São Paulo: Makroon Books, 1996.

CZINKOTA, Michael R.; DICKSON, Peter R.; DUNNE, Patrick; GRIFFIN, Abbie. Marketing: as melhores práticas. Porto Alegre, RS: Bookman, 2002. 


\section{E-BIT. Relatório Semanal de Avaliação. São Paulo, set. 2009}

GARRY, Tony; HARWOOD, Tracy. The moderating influence of client sophistication on relationships within business-to-business credence service markets. The Journal of Business \& Industrial Marketing, Santa Barbara, EUA, n. 5, v. 24, 2009.

GIANGRANDE, Vera de M.; CYMBAUM, John J. O.; MÁLACCO, Rejane L. S.; CODA, Roberto; FONSECA, Maria A. Marketing de relacionamento no varejo: qualidade de atendimento, mix de serviços, Data Warehouse, pesquisa de mercado, comitês de clientes, ombudsman. São Paulo: Atlas, 1999.

GRAYSON, Kent. Friendship Versus Business in Marketing Relationships. Journal of Marketing, Chicago, EUA, vol. 71, num. 4, oct. 2007.

GREENBERG, Paul. CRM - conquista e lealdade de clientes em tempo real na Internet: na velocidade da luz. Rio de Janeiro: Campus, 2001.

GUNDLACH, Gregory T.; BOLUMOLE, Yemisi A.; ELTANTAWY, Reham A.; FRANKEL, Robert. The changing landscape of supply chain management, marketing channels of distribution, logistics and purchasing. The Journal of Business \& Industrial Marketing, Santa Barbara, vol. 21, num. 7, 2006.

HARRISON, Alan; HOEK, Remko van. Estratégia e gerenciamento de logística. São Paulo: Futura, 2003.

KALAKOTA, Ravi; ROBINSON, Marcia. E-Business: estratégias para alcançar o sucesso no mundo digital. Porto Alegre: Bookman, 2002.

KARSAKLIAN, Eliane. Cybermarketing. São Paulo, SP: Atlas, 2001.

KOTLER, Philip; ARMSTRONG, Gary. Princípios de marketing. São Paulo: Prentice Hall, 2003.

LAKATOS, Eva Maria.; MARCONI, Marina de Andrade. Técnicas de pesquisa: planejamento e execução de pesquisas, amostragens e técnicas de pesquisas, elaboração, análise e interpretação de dados. 4. ed. São Paulo: Atlas, 1999.

LAS CASAS, Alexandre Luzzi (Org.); GARCIA, Maria Tereza (Org.). Estratégias de marketing para varejo: inovações e diferenciações estratégicas que fazem a diferença no marketing de varejo. São Paulo: Novatec Editora, 2007.

LIMEIRA, Tania M. Vidigal. E-Marketing. 2. ed. São Paulo: Saraiva, 2007.

MADRUGA, Roberto. Guia de implementação de marketing de relacionamento e CRM. São Paulo: Atlas, 2006.

MCKINLEY-FLOYD, Lydia; SHRESTHA, Nanda. Segmentation strategies for non-profits: mining the emerging market of "black gold". The Journal of Business \& Industrial Marketing, Santa Barbara, EUA, n. 6, 2008.

MORAIS, Felipe. Planejamento estratégico digital: a importância de planejar a comunicação da marca no ambiente digital. Rio de Janeiro: Brasport, 2009.

PRODANOV, Cleber Cristiano; FREITAS, Ernani Cesar de. Metodologia do trabalho científico: métodos e técnicas da pesquisa e do trabalho acadêmico. Novo Hamburgo, RS: Feevale, 2009.

RAO, Shashank; GOLDSBY, Thomas J.; IYENGAR, Deepak. The marketing and logistics efficacy of online sales channels. International Journal of Physical Distribution \& Logistics Management, Bradford, vol. 39, num. 2, 2009.

REEDY, Joel; SCHULLO, Shauna; ZIMMERMAN, Kenneth. Marketing eletrônico: a integração de recursos eletrônicos ao processo de marketing. Porto Alegre, RS: Bookman, 2001.

RUDIO, Franz Victor. Introdução ao projeto de pesquisa científica. Petrópolis, RJ: Vozes, 1985. 132

SABATINO, Luiz. Fidelização: a ferramenta de marketing que promove relacionamentos duradouros com os clientes. Rio de Janeiro: Reichmann \& Affonso Editores, 2003. 
SCHULMAN, S. A. Understanding digital marketing: marketing strategies for engaging the digital generation. Choice, Middletown, vol. 46, n. 10, Jun. 2009.

SHETH, Jagdish N.; ESHGHI, Abdolreza; KRISHNAN, Balaji C. Marketing na internet. Porto Alegre: Artmed, 2002.

TELLES, Renato; STREHLAU, Vivian Iara. Canais de marketing e distribuição: conceitos, estratégias, gestão, modelos de decisão. São Paulo: Saraiva, 2006.

VASSOS, Tom. Marketing estratégico na Internet. São Paulo: Makron Books, 1997. 